\title{
Factors Associated with Anger among Male Adolescents in Western Iran: An Application of Social Cognitive Theory
}

\author{
Mohammad Sadegh Abedzadeh Zavareh ${ }^{1}$, Shamsaddin Niknami ${ }^{1} \&$ Ali Reza Hidarnia ${ }^{1}$ \\ ${ }^{1}$ Department of Health Education, Faculty of Medical Sciences, Tarbiat Modares University, Tehran, Iran \\ Correspondence: Shamsaddin Niknami, Jalal Ale Ahmad Ave, Tehran 111-14115, Tehran, Iran. Tel: \\ 98-218-288-3569. E-mail: Niknamis@modares.ac.ir
}

Received: December 28, 2014 Accepted: March 10, 2015 Online Published: May 20, 2015

doi:10.5539/gjhs.v7n6p338 URL: http://dx.doi.org/10.5539/gjhs.v7n6p338

\begin{abstract}
Introduction: Anger can be defined a natural emotional response that is gradually formed to protect us in dealing with threats, damages, assaults, and failures; while hatred is a change of attitude which is built following the persistence of anger towards a subject or an individual. One of the main reasons of adolescents' reference to the counseling centers is their anger accompanied by violence.
\end{abstract}

Objective: This study aims to determine the social cognitive factors associated with anger among a population of adolescents in the west of Iran based on the social cognitive theory.

Methodology: Samples were selected based on multi-stage cluster sampling. Method including the first and the second-grade male high school students from Ilam town $(\mathrm{N}=360)$. The Spielberger's anger questionnaire (STAXI 2) and a self-designed questionnaire based on Bandura's social cognitive theory were employed as the data collection instruments in the present study.

Results: Of the selected population, 200 students were the first-grade and 160 students were the second-grade students. 135 students were the first child of the family, 150 students were the second or the third birth, and 75 students were the fifth or above in their families. Descriptive tests and correlation analysis were used to conduct the statistical analysis. Although there was a significant and inverse relationship between all the components of the theory and anger, the strongest relationship was seen in self-efficacy $(-0.585)$ and the weakest relationship was seen in modeling $(-0.297)$.

Discussion and Conclusion: If was concluded that helping people to know their abilities and have a better personal judgment in this case, can influence their anger control. In addition, the process of stress management can effectively increase an individual's emotional coping.

Keywords: anger, social cognitive theory, adolescent, student, Iran

\section{Introduction}

Anger can be defined as a natural emotional response that is gradually formed to protect us in dealing with threats, damages, assaults, and failures; while hatred is a change of attitude which is built following the persistence of anger towards a subject or an individual. Additionally, aggression is a visible behavior that is usually aimed at harming others or something (Nicolet, 2004). Anger can also be considered as a satisfying emotion or a devastating one. It activates our internal systems and provides us to face with the potential risks surrounding (Taylor \& Novaco, 2005).

Anger related issues such as coping behavior, hostility and aggression are among the main reasons behind the reference of adolescents, the young adults and even children to mental health counseling centers (Maleki, Fallahi, Rahgooi, \& Rahgozar, 2011).

Several researchers have claimed that an individual's inability to express their feelings effectively has a significant relationship with anger and this issue can be taken into account as one of the leading factors for addiction reappearance (Schonfeld et al., 2000). Similarly, some findings have revealed that there is a significant relationship between the amount of external anger demonstration with the abuse of alcohol, drugs and tobacco. Anger has also been specified as a predictor factor for drug abuse such as cocaine (Kirby, Lamb, Iguchi, Husband, \& Platt, 1995; Wills, Sandy, Yaeger, Cleary, \& Shinar, 2001). As well, the environmental stresses directly affect delinquency and aggression, and anger caused by stressful environments is in the form of a 
mediator for risky behaviors (Bakhshipour R., Mahmood Alilou, \& Irani, 2008; Clark, Wood, Cornelius, Bukstein, \& Martin, 2003).

Anger has also been recognized as one of the factors affecting students' aggression (Maleki et al., 2011) as well as an effective factor which has an impact on the interaction between parents and children (Sanders et al., 2004).

In many studies, researchers have mentioned the specification of the effective role of surrounding factors on adolescent anger such as socio-economic, political, and cultural problems alongside strengthening and empowering adolescents to cope with anger and have internal management among the strategies which can have an effect on anger control and its development and ultimately reduce aggressive and antisocial behavior (Hashemian, Shafieabadi, \& Soudani, 2008).

As a result, it is concluded that the effects of weakness and inability in anger management is higher than personal inconveniences and damages to the interpersonal relationships. These effects can also lead to disturbance in public health, appearance of public incompatibility, and the harmful consequences of aggressive behaviors. In case this powerful emotion is not controlled properly, it can prevent overall success and optimal functioning of individuals, groups and communities (Naveedy, 2009).

Numerous studies have been conducted in conjunction with anger, and a number of factors such as self-awareness, social support, behavioral factors, self-control, self-efficacy, relaxation, self-monitoring and as a whole cognitive-behavioral factors have been cited as the factors which have an impact on it (Lombardo, Tan, Jensen, \& Anderson, 2005; Mohammadiarya et al., 2012; Shokoohi-Yekta, Zamani, \& Parand, 2010; Shokoohi-Yekta, Zamani, Parand, Ayazi, \& Lotfi, 2011).

In the present study, social cognitive theory was employed to consider the above-mentioned factors. This theory, designed and established by Albert Bandura, assumes that human behavior can be illustrated by a two-directional triple causation. These factors include behavioral factors, personal factors, and environmental ones (Glanz, Rimer, \& Viswanath, 2008). Since these factors are considered and employed in this theory, the main objective of the present study is to determine the social cognitive factors associated with anger among adolescents in western Iran based on the social cognitive theory.

\section{Materials and Method}

\subsection{Subject}

All the first and the second-grade male high school students comprised the statistical population of the present study. The participants $(\mathrm{N}=360)$ were from 4 high schools selected through cluster sampling among 16 public male high schools. Samples were selected using random and classified sampling (based on the educational years) between the first and the second-grade students. The inclusion criteria were studying at the first and the second year of study in public high schools, having no mental illness certified by a physician, taking no psychiatric medications, and having consent to participate in the project (all the participants in the project endorsed a written consent). Those who did not have the mentioned conditions were excluded. In terms of the ethical approval, this project was confirmed by the ethics committee of Tarbiat Modares University, Tehran.

\subsection{Instruments}

Two questionnaires including the Persian version of Spielberger anger test (STAXI 2) and a self-designed questionnaire based on the social cognitive theory were administered. The anger test (STAXI 2) with 57 items was prepared by Spielberger in 1999. This questionnaire is composed of 6 scales (state anger, trait anger, anger expression out, anger expression in, anger control out, and anger control in); and 5 sub-scales (feeling angry, fill like expression anger verbally, fill like expression anger physically, angry temperament, and angry reaction) and general anger expression index. Responses to the Spielberger's anger questionnaire were based on a four-scale degree ranging from (never=1) to (a lot=4), and also, (rarely=1) to (always=4).Asghari Moghadam et al. (2011), determined the validity and reliability of Persian version of Spielberger's anger questionnaire. Internal consistency for state anger, trait anger and general anger index in their study were $0.91,0.82$, and 0.81 respectively. In order to measure the constructs of the social cognitive theory in the self-designed questionnaire, the number of questions and the Cronbach's alpha coefficients are summarized in Table 1.

The questionnaire of social cognitive theory contained several construct amongst them, the knowledge construct was in the form of true, false and I don't know; and the others were in the form of five-choice Likert-scale ranging from completely disagree to completely agree. The demographic questions included grade, field of study, family size, birth order, age, father's education, mother's education, and father's and mother's occupations.

The questionnaires were completed from November 13th to November 30th, 2014. For data collection the 
researcher referred to 4 high school of Ilam town and after coordinating to school principal the questionnaire were distributed between first and second year high school students. Before completion the questionnaire by the students about ten minutes the researcher explained about the aims of the study and how to complete the questionnaires.

Descriptive statistics and inter-correlation analysis tests were used, to analyze the data using SPSS version 16.

Table 1. Internal consistency of social cognitive variables

\begin{tabular}{|c|c|c|c|}
\hline Variables & $\begin{array}{l}\text { Number of } \\
\text { Items }\end{array}$ & $\begin{array}{l}\text { Cronbach's } \\
\text { alpha }(\alpha)\end{array}$ & Define variables \\
\hline Knowledge & 4 & 0.573 & Learning facts and gaining insights \\
\hline Modeling & 5 & 0.618 & observational learning \\
\hline Outcome expectancies & 5 & 0.768 & $\begin{array}{l}\text { Value a person places on the probable outcomes that result from } \\
\text { performing a behavior }\end{array}$ \\
\hline Outcome expectation & 5 & 0.723 & $\begin{array}{l}\text { Anticipation of the probable outcomes that would ensue as a } \\
\text { result of engaging in the behavior under discussion }\end{array}$ \\
\hline Social support & 4 & 0.85 & Social circumstances or conditions that surround a person \\
\hline emotional coping & 4 & 0.76 & $\begin{array}{l}\text { Techniques employed by the person to control the emotional and } \\
\text { physiological states associated with acquisition of a new } \\
\text { behavior }\end{array}$ \\
\hline self-efficacy & 4 & 0.72 & Confidence in one's ability to pursue a behavior \\
\hline goal setting or self-control & 4 & 0.787 & $\begin{array}{l}\text { Setting goals and developing plans to accomplish chosen } \\
\text { behavior }\end{array}$ \\
\hline
\end{tabular}

\section{Results}

All the participants in the first and the second-grade high school students aged between 15 and 16 years. $10 \%$ of students' fathers and $16.1 \%$ of their mothers were illiterate. About $33.1 \%$ of families were relatively populated (6 and above). It was also revealed that $37.5 \%$ of the participants were the first child of the family. About $70.3 \%$ of students were 15 years old, and the rest (29.7\%) were 16 years old (Table 2).

Table 2. Socio demographic characteristics of study subjects

\begin{tabular}{lll}
\hline Characteristics & $N$ & $\%$ \\
\hline Age & 253 & 70.3 \\
15 & 107 & 29.7 \\
16 & & \\
Students Educational Grades & 200 & 55.6 \\
1 th & 160 & 44.4 \\
2 th & & \\
Father educational level & 36 & 10 \\
Illiterate & 188 & 52.2 \\
Under diploma & 136 & 37.8 \\
Diploma and higher & & \\
Mother educational level & 58 & 16.1 \\
Illiterate & 242 & 67.2 \\
Under diploma & 60 & 16.7 \\
Diploma and higher & & \\
\hline
\end{tabular}




\begin{tabular}{lll}
\hline Family dimension & & \\
3 & 9 & 2.5 \\
$4-5$ & 232 & 64.4 \\
6 and highest & 119 & 33.1 \\
Rank of birth & & \\
$\quad$ th & 135 & 37.5 \\
$2 \& 3$ th & 150 & 41.7 \\
$4^{\text {th }}$ and highest & 75 & 20.8 \\
\hline
\end{tabular}

All of the 8 measured scales had a significant and inverse relationship with anger so that the strongest and the weakest relationships were between anger and self-efficacy and anger and modeling, respectively (Table 3). Also there was a significant relationship between the 8 components (the strongest relationship was between self-efficacy and emotional coping and the weakest relationship was between knowledge and social support).

Table 3. Means, standard deviations, and inter-correlations for anger and social cognitive variables

\begin{tabular}{|c|c|c|c|c|c|c|c|c|c|c|c|}
\hline Variables & 1 & 2 & 3 & 4 & 5 & 6 & 7 & 8 & 9 & Mean & SD \\
\hline 1. Anger (AX.Index) & - & & & & & & & & & 40.12 & 1.37 \\
\hline 2. Modeling & $-.279 * *$ & - & & & & & & & & 12.7 & 3.51 \\
\hline $\begin{array}{l}\text { 3. Social support } \\
\text { (Environment) }\end{array}$ & $-.358 * *$ & $.498 * *$ & - & & & & & & & 9.83 & 3.32 \\
\hline $\begin{array}{l}\text { 4.Outcome } \\
\text { expectation }\end{array}$ & $-.410 * *$ & $.341 * *$ & $.447 * *$ & - & & & & & & 15.83 & 3.35 \\
\hline 5.Self - control & $-.497 * *$ & $.244 * *$ & $.334 * *$ & $.492 * *$ & - & & & & & 11.03 & 2.93 \\
\hline 6.Emotional coping & $-.547 * *$ & $.307 * *$ & $.404 * *$ & $.365^{* *}$ & $.453 * *$ & - & & & & 8.93 & 3.64 \\
\hline $\begin{array}{l}\text { 7.Outcome } \\
\text { expectancy }\end{array}$ & $-.435 * *$ & $.354 * *$ & $.426^{* *}$ & $.581 * *$ & $.543 * *$ & $.434 * *$ & - & & & 13.44 & 3.99 \\
\hline 8.Knowledge & $-.423 * *$ & $.179 * *$ & $.258 * *$ & $.349 * *$ & $.391 * *$ & $.231 * *$ & $.374 * *$ & - & & 5.19 & 1.91 \\
\hline 9.Self-efficacy & $-.585^{* *}$ & $.414 * *$ & $.431 * *$ & $.431 * *$ & $.493 * *$ & $.499 * *$ & $.456^{* *}$ & $.323 * *$ & - & 8.69 & 2.76 \\
\hline
\end{tabular}

** Correlation is significant at the 0.01 level (2-tailed).

\section{Discussion and Conclusion}

According to the findings of the current study, there was a significant and inverse relationship between the general expression of anger and all the components of the social cognitive theory.

There is a significant relationship between the anger scale and modeling. Although this relationship is weaker in comparison with other components, it was revealed that an individual directly copies behaviors, and others' behaviors have instigating effects on a person. Some researcher have stressed on such issue and revealed that the modeling can have an impact on students' anger (Gansle, 2005).

Likewise, there was a significant relationship between social support and anger. In this way, having social support can be highly helpful to the creation of a new behavior, or quitting a wrong behavior (anger). In some other studies the family environment was mentioned that can influence the trait anger (Lopez \& Thurman, 1993). Moreover, in one study on HIV positive patients it was confirmed that social support reduces the amount of anger (Whitehead, Hearn, \& Burrell, 2014), while in another study carried out on patients under angiographic treatment it was revealed that there was a significant and inverse relationship between the social support and anger expression (León, Nouwen, Sheffield, Jaumdally, \& Lip, 2010). It has been demonstrated that people who were supported by religious communities have gone through lesser anger (Márquez-González, López, Romero-Moreno, \& Losada, 2012). Furthermore some other researchers showed a significant relationship 
between social support and more social ties with anger (Ha \& Ingersoll-Dayton, 2011).

It was revealed that there was a significant relationship between outcome expectation and the anger. The outcome expectation here refers to the physical consequences (positive and negative consequences), social approval or disapproval and their positive or negative evaluation (Bandura, 2004). Findings provided by Mauss, highlighted that anger control was in association with the negative results. There was similarly a significant relationship between emotion control and the positive results; and as it was noted, there was a relationship between the emotion control and anger control. In fact, the positive results influence anger intermediately (Mauss, Cook, \& Gross, 2007).

As it was shown in Table 3, there was a significant relationship between the anger and self-control, self-control implies that a person sets several primary and final goals and tries to reduce anger. Studies by Gilliom and others are consistent with the findings of the present study (Davey, Day, \& Howells, 2005).

Additionally, Novako in a series of studies showed that self-control can have some bearing on the anger of 17 to 42 year-old individuals (Novaco, 1976). Beck also concluded that self-control has an impact on anger (Beck \& Fernandez, 1998).

According to the findings illustrated in Table 3, there was a significant relationship between the anger and emotional coping. The emotional coping refers to strategies employed by an individual in order to control emotional and physiological states in association with showing a behavior. It was revealed that the emotional state can be influential to self-control. This means that the emotional state can indirectly influence the anger (Singh et al., 2011). Another studies showed that there is a significant relationship between emotion control and anger (Garnefski et al., 2002; Martin \& Dahlen, 2005). It was also shown that there is a relationship between relaxation and aggression (Novaco, 1976).

There was a significant relationship between outcome expectancies and anger. The consequence value here means the value an individual places on the possible consequences of performing a particular behavior. Some researchers carried out a study on mouth and teeth hygiene of pregnant women and showed that the more the benefits and the value of a behavior for an individual were proportional to the higher probability of showing that behavior. These findings were consistent with the results of the present study (Shamsi et al., 2014).

There is a significant relationship between anger and knowledge. This may possibly originate from this point that the more an individual knows about anger and is aware of it, the more their ability for and motivation towards anger control and the importance of control. Mohammadiarya in a study showed that self-knowledge can be effective on aggression and anger management which was in consonance with the results of the current study (Mohammadiarya, et al., 2012).

According to the findings shown in Table 3, there was a significant relationship between the anger and the self-efficacy. The self-efficacy here means an individual's judgment about their abilities in order to enhance them. A significant and inverse relationship between self-efficacy and anger control was proved (Lombardo, et al., 2005). Zimmerman correspondingly reached to this conclusion that self-efficacy can have an effect on learning, emotional response, as well as students' selection of behavior (Zimmerman, 2000). Zareban also in a series of studies on type-II diabetic patients concluded that teaching self-efficacy can lead to a reduction in an individual's blood sugar level (Zareban, Niknami, \& Rakhshani, 2013).

\section{Acknowledgements}

Many thanks to the officials and authorities of Tarbiat Modares University in Tehran, Iran, who provided the required funding for this project. Also many thanks to all the educational personnel, including administrators as well as students who contributed to this project.

\section{References}

Asghari Moghadam M., A., Moghaddasin, M., \& Dibajnia, P. (2011). The study of reliability and validity of Persian version of state-trait anger (STAXI-2), in a clinical sample. Clinical Psy and Clinical Personality, 3(5), 75-92. [In Persian]

Bakhshipour R., A., Mahmood Alilou, M., \& Irani, S. (2008). The Comparison of Personality Traits, Personality Disorders, and Problem-solving Strategies in Self-introduced Addicts and Normal Population. [Original Research]. Iranian Journal of Psychiatry and Clinical Psychology, 14(3), 289-297. Retrieved from http://ijpcp.iums.ac.ir/browse.php?a_id=571\&slc_lang=en\&sid=1\&printcase=1\&hbnr=1\&hmb=1

Bandura, A. (2004). Health promotion by social cognitive means. Health education \& behavior, 31(2), 143-164. http://dx.doi.org/ 10.1177/1090198104263660 
Beck, R., \& Fernandez, E. (1998). Cognitive-behavioral self-regulation of the frequency, duration, and intensity of anger. Journal of Psychopathology and Behavioral Assessment, 20(3), 217-229. Retrieved from http://link.springer.com/article/10.1023/A:1023063201318\#

Clark, D. B., Wood, D. S., Cornelius, J. R., Bukstein, O. G., \& Martin, C. S. (2003). Clinical practices in the pharmacological treatment of comorbid psychopathology in adolescents with alcohol use disorders. Journal of substance abuse treatment, 25(4), 293-295. http://dx.doi.org/ 10.1016/S0740-5472(03)00119-3

Davey, L., Day, A., \& Howells, K. (2005). Anger, over-control and serious violent offending. Aggression and Violent Behavior, 10(5), 624-635. http://dx.doi.org/10.1016/j.avb.2004.12.002

Gansle, K. A. (2005). The effectiveness of school-based anger interventions and programs: A meta-analysis. Journal of School Psychology, 43(4), 321-341. http://dx.doi.org/ 10.1016/j.jsp.2005.07.002

Garnefski, N., Van Den Kommer, T., Kraaij, V., Teerds, J., Legerstee, J., \& Onstein, E. (2002). The relationship between cognitive emotion regulation strategies and emotional problems: comparison between a clinical and a non-clinical sample. European Journal of Personality, 16(5), 403-420. http://dx.doi.org/10.1002/per.458

Glanz, K., Rimer, B. K., \& Viswanath, K. (2008). Health behavior and health education: theory, research, and practice. John Wiley \& Sons.

Ha, J.-H., \& Ingersoll-Dayton, B. (2011). Moderators in the relationship between social contact and psychological distress among widowed adults. Aging \& mental health, 15(3), 354-363. http://dx.doi.org/10.1080/13607863.2010.519325

Hashemian, F., Shafieabadi, A. E., \& Soudani, M. (2008). Effect of anger control skills training on individual-social adjustmentof first-grade female secodary education students in mahshahr. Knowledge. Retrieved from http://en.journals.sid.ir/ViewPaper.aspx?ID=181111

Kirby, K. C., Lamb, R., Iguchi, M. Y., Husband, S. D., \& Platt, J. J. (1995). Situations occasioning cocaine use $\begin{array}{llll}\text { and cocaine abstinence } & \text { 1241-1252. }\end{array}$ http://dx.doi.org/10.1046/j.1360-0443.1995.90912418.x

León, T. C., Nouwen, A., Sheffield, D., Jaumdally, R., \& Lip, G. Y. H. (2010). Anger rumination, social support, and cardiac symptoms in patients undergoing angiography. British Journal of Health Psychology, 15(4), 841-857. http://dx.doi.org/10.1348/135910710x491360

Lombardo, E. R., Tan, G., Jensen, M. P., \& Anderson, K. O. (2005). Anger management style and associations with self-efficacy and pain in male veterans. The Journal of Pain, 6(11), 765-770. http://dx.doi.org/10.1016/j.jpain.2005.07.003

Lopez, F. G., \& Thurman, C. W. (1993). High-Trait and Low-Trait Angry College Students: A Comparison of Family Environments. Journal of Counseling \& Development, 71(5), 524-527. http://dx.doi.org/10.1002/j.1556-6676.1993.tb02235.x

Maleki, S., Fallahi, K. M., Rahgooi, A., \& Rahgozar, M. (2011). The effect of anger management training in groups on aggression of 12-15 years old male students. Iran journal of nursing (ijn). Retrieved from http://en.journals.sid.ir/ViewPaper.aspx?ID=212392

Márquez-González, M., López, J., Romero-Moreno, R., \& Losada, A. (2012). Anger, spiritual meaning and support from the religious community in dementia caregiving. Journal of religion and health, 51(1), 179-186. http://dx.doi.org/ 10.1007/s10943-010-9362-7

Martin, R. C., \& Dahlen, E. R. (2005). Cognitive emotion regulation in the prediction of depression, anxiety,

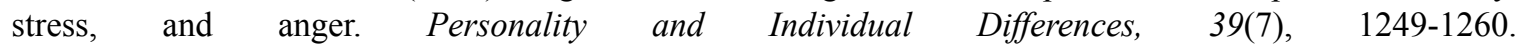
http://dx.doi.org/10.1016/j.paid.2005.06.004

Mauss, I. B., Cook, C. L., \& Gross, J. J. (2007). Automatic emotion regulation during anger provocation. Journal of Experimental Social Psychology, 43(5), 698-711. http://dx.doi.org/ 10.1016/j.jesp.2006.07.003

Mohammadiarya, A., Sarabi, S. D., Shirazi, M., Lachinani, F., Roustaei, A., Abbasi, Z., \& Ghasemzadeh, A. (2012). The effect of training self-awareness and anger management on aggression level in Iranian middle school students. Procedia-Social and Behavioral Sciences, 46, 987-991. http://dx.doi.org/ 10.1016/j.sbspro.2012.05.235

Naveedy, A. (2009). The Efficacy of Anger Management Training on Adjustment Skills of High School Male Students in Tehran. [Original Research]. Iranian Journal of Psychiatry and Clinical Psychology, 14(4), 
394-403. Retrieved from http://ijpcp.iums.ac.ir/browse.php?a_code=A-10-1-319\&slc_lang=en\&sid=1

Nicolet, I. A. (2004). The second step violence prevention program: Effectiveness of a brief social skills curriculum with elementary-age children. Capella University.

Novaco, R. W. (1976). Treatment of chronic anger through cognitive and relaxation controls. Journal of Consulting and Clinical Psychology, 44(4), 681. doi: http://dx.doi.org/10.1037/0022-006X.44.4.681

Sanders, M. R., Pidgeon, A. M., Gravestock, F., Connors, M. D., Brown, S., \& Young, R. W. (2004). Does parental attributional retraining and anger management enhance the effects of the Triple P-Positive Parenting Program with parents at risk of child maltreatment? Behavior Therapy, 35(3), 513-535. http://dx.doi.org/10.1016/S0005-7894(04)80030-3

Schonfeld, L., Dupree, L. W., Dickson-Fuhrmann, E., Royer, C. M., McDermott, C. H., Rosansky, J. S., . . Jarvik, L. F. (2000). Cognitive-behavioral treatment of older veterans with substance abuse problems. Journal of Geriatric Psychiatry and Neurology, 13(3), 124-129. http://dx.doi.org/ $10.1177 / 089198870001300305$

Shamsi, M., Hidarnia, A., Niknami, S., Rafiee, M., Zareban, I., \& Karimy, M. (2014). The Effect of Educational Program on Increasing Oral Health Behavior among Pregnant Women: Applying Health Belief Model. Health Education \& Health Promotion, 1(2), 21-36. Retrieved from http://hehp.modares.ac.ir/article_10651_72.html

Shokoohi-Yekta, M., Zamani, N., \& Parand, A. (2010). Efficacy of anger management training based on cognitive-behavioral approach on mothers of children with mental retardation: 1-year follow-up. Procedia-Social and Behavioral Sciences, 5, 1434-1437. http://dx.doi.org/10.1016/j.sbspro.2010.07.302

Shokoohi-Yekta, M., Zamani, N., Parand, A., Ayazi, M., \& Lotfi, S. (2011). Effects of anger management workshops on mothers of children with special needs. Procedia-Social and Behavioral Sciences, 30, 159-162. http://dx.doi.org/10.1016/j.sbspro.2011.10.031

Singh, N. N., Lancioni, G. E., Winton, A. S., Singh, J., Singh, A. N., \& Singh, A. D. (2011). Peer with intellectual disabilities as a mindfulness-based anger and aggression management therapist. Research in developmental disabilities, 32(6), 2690-2696. http://dx.doi.org/ 10.1016/j.ridd.2011.06.003

Taylor, J. L., \& Novaco, R. W. (2005). Anger treatment for people with developmental disabilities: A theory, evidence and manual based approach. John Wiley \& Sons.

Whitehead, N. E., Hearn, L. E., \& Burrell, L. (2014). The association between depressive symptoms, anger, and perceived support resources among underserved older HIV positive Black/African American adults. AIDS patient care and STDs, 28(9), 507-512. http://dx.doi.org/ 10.1089/apc.2014.0126.

Wills, T. A., Sandy, J. M., Yaeger, A. M., Cleary, S. D., \& Shinar, O. (2001). Coping dimensions, life stress, and adolescent substance use: a latent growth analysis. Journal of abnormal psychology, 110(2), 309. http://dx.doi.org/10.1037/0021-843X.110.2.309

Zareban, I., Niknami, S., \& Rakhshani, F. (2013). The Effect of Self Efficacy Education Program on Reducing Blood Sugar Levels in Patients with Type 2 Diabetes. Health Education \& Health Promotion, 1(1), 67-79.retrieved from http://www.sid.ir/EN/VEWSSID/J_pdf/5067620130107.pdf

Zimmerman, B. J. (2000). Self-Efficacy: An Essential Motive to Learn. Contemporary Educational Psychology, 25(1), 82-91. http://dx.doi.org/10.1006/ceps.1999.1016

\section{Copyrights}

Copyright for this article is retained by the author(s), with first publication rights granted to the journal.

This is an open-access article distributed under the terms and conditions of the Creative Commons Attribution license (http://creativecommons.org/licenses/by/3.0/). 